\title{
COMPARAÇÃO DE METODOLOGIAS DO TESTE DE TETRAZÓLIO PARA SEMENTES DE CAFEEIRO
}

\author{
COMPARING THE TETRAZOLIUM TEST METHODOLOGIES \\ FOR SEEDS OF COFFEE SHRUB
}

\author{
João Batista Zonta ${ }^{1}$; Leandro Torres de Souza ${ }^{1}$; Denise Cunha Fernandes dos Santos Dias ${ }^{1}$; \\ Eveline Mantovani Alvarenga ${ }^{1}$
}

\section{RESUMO}

O teste de tetrazólio apresenta-se como uma alternativa promissora para a avaliação rápida da viabilidade das sementes, sendo que para cafeeiro há duas metodologias descritas. O presente trabalho teve como objetivo verificar, entre estas metodologias existentes, qual a mais eficiente para a determinação rápida da viabilidade e do vigor. Para tal, sementes de 4 lotes foram submetidas as seguintes metodologias: 1) embebição por 24 horas a $30^{\circ} \mathrm{C}$; corte da porção do endosperma que contém o embrião; exposição desta porção à solução de tetrazólio a $0,1 \%$, durante 16 horas a $35^{\circ} \mathrm{C}$, retirando em seguida o embrião com ajuda de um bisturi para posterior avaliação; 2) embebição por 24 horas a $30^{\circ} \mathrm{C}$; retirada do embrião e exposição à solução de tetrazólio a $0,1 \%$, durante 16 horas a $35^{\circ} \mathrm{C}$, para posterior avaliação. Para comparação dos resultados obtidos foi montado o teste de germinação, avaliando-se a porcentagem final de germinação e o vigor ( $1^{\text {a }}$ contagem de germinação). Os resultados indicaram que a metodologia 2 mostrouse mais promissora para a avaliação da viabilidade e do vigor de sementes de cafeeiro, pois os valores obtidos se equivaleram aos valores do teste de germinação. A metodologia 1 não foi eficiente pois apresentou problemas quanto à coloração dos embriões, gerando assim dúvida durante a avaliação da viabilidade das sementes.

Palavras-chave: Viabilidade, teste rápido, eficiência.

\begin{abstract}
The tetrazolium test is a promising alternative for rapid evaluation of the seed viability. Two described methodologies are available for coffee shrub. Thus, this study was conducted to verify what methodology is more efficient for fast determination of both viability and energy. So, seeds from four lots were subjected to procedures as follows. 1) Soaking for 24 hours at $30^{\circ} \mathrm{C}$; cutting the portion of the endosperm containing the embryo; exposure of this portion to $0.1 \%$ tetrazolium solution for 16 hours at $35^{\circ} \mathrm{C}$; then, the embryo is removed with the aid of a bistoury for subsequent evaluation. 2) Soaking for 24 hours at $30^{\circ} \mathrm{C}$; removal of the embryo and its exposure to $0.1 \%$ tetrazolium solution for 16 hours at $35^{\circ} \mathrm{C}$ for subsequent evaluation. To comparing the results, the germination test accomplished and the final percent germination and the vigor ( $1^{\text {st }}$ germination counting) were evaluated. The methodology 2 showed to be more promising for the evaluation of both viability and vigor of coffee shrub seeds, since the obtained values were equal to those of the germination test. The methodology 1 was not efficient, as showing problems concerning to coloration of the embryos, therefore generating doubts during the evaluation of the seed viability.
\end{abstract}

Key-words: Viability, test fast, efficiency.

\section{INTRODUÇÃO}

Um dos grandes problemas referentes à cultura do cafeeiro está relacionado às sementes que são caracterizadas, fisiologicamente, como rápidas perdedoras de viabilidade (Vargas, 1955; Bendaña, 1962;
Popinigis, 1977; Silva \& Dias, 1985). Este atributo, quando associado à lentidão representada por 30 dias para a obtenção dos resultados no teste de germinação (Brasil, 1992), leva ao problema de se chegar, num dado instante, a uma informação de viabilidade que pode não expressar a real qualidade do lote analisado.

1 Universidade Federal de Viçosa, Dep. de Fitotecnia, Viçosa, MG, Campus Universitário, Fone: (0XX31) 38915738, e-mail: jobazonta@hotmail.com

Fecha de Recepción: 2 Abril 2007

Fecha de Aceptación: 10 Junio 2007 
Diante desta situação, uma série de pesquisas foi conduzida procurando abreviar o prazo requerido para a obtenção dos resultados de viabilidade, por intermédio de métodos indiretos passiveis de correlação com o teste de germinação, como o teste de avaliação visual de exsudatos (Sera \& Miglioranza 2000), o teste do $\mathrm{pH}$ do exsudato-fenolftaleína (Figueiredo 2000) e o teste de tetrazólio (Delouche \& Baskin, 1973).

O teste de tetrazólio tem se mostrado como uma alternativa interessante pela qualidade e rapidez na determinação da viabilidade e do vigor da semente, permitindo obter resultados, de modo geral, em menos de 24 horas (Delouche et al., 1976; França Neto et al., 1988; Costa \& Marcos Filho, 1994). O teste baseia-se na atividade das enzimas desidrogenases, particularmente a desidrogenase do ácido málico que reduz o sal de tetrazólio nos tecidos vivos das sementes, onde íons de $\mathrm{H}^{+}$são transferidos para o referido sal. Quando a semente é imersa na solução de tetrazólio, ocorre a reação de redução nas células vivas resultando na formação de um composto vermelho, não difusível, conhecido como trifenilformazan, indicando haver atividade respiratória nas mitocôndrias e, conseqüentemente, que o tecido é viável (vivo), conforme França Neto et al., (1999). Tecidos mortos (não viáveis) não reagem com a solução conservando a sua cor natural (Delouche et al., 1976). Trata-se de um teste que, pela observação da coloração obtida nas diferentes partes da semente, permite determinar a presença, a localização e a natureza das alterações nos tecidos das sementes (França Neto et al., 1999), permitindo ainda identificar, muitas vezes, as causas da perda da viabilidade e do vigor.

No Brasil, estudos referentes ao desenvolvimento de metodologia e à utilização do teste de tetrazólio já foram feitos para sementes de algumas espécies, destacando-se soja (França Neto et al., 1988 e 1999), feijão (Bhering et al., 1996 e 1999), milho (Dias \& Barros, 1999), algodão (Vieira \& Pinho, 1999), amendoim (Bittencourt et al., 1997; Bittencourt \& Vieira, 1996 e 1999), café (Araújo et al., 1997; Vieira et al., 1998), gramíneas forrageiras (Dias \& Alves, 2001 a,b), quiabo (Eichelberger \& Moraes, 2001), abóbora (Barros et al., 2005) e melancia (Bhering et al., 2005).

Assim, várias pesquisas têm sido desenvolvidas procurando a obtenção precoce dos resultados de viabilidade, bem como a padronização do teste de tetrazólio para cada uma das espécies estudadas. Para sementes de café, duas metodologias foram citadas. A principal diferença entre estas metodologias é a forma de exposição do embrião à solução de tetrazólio.

O objetivo do trabalho foi verificar, entre as metodologias existentes do teste de tetrazólio, para sementes de cafeeiro, qual é a mais eficiente para a determinação rápida de viabilidade e vigor.

\section{MATERIAIS E MÉTODOS}

A pesquisa foi desenvolvida no Laboratório de Sementes do Departamento de Fitotecnia da Universidade Federal de Viçosa, utilizando-se quatro lotes de sementes de cafeeiro (Coffea arabica L.), buscando-se obter materiais com diferentes níveis de germinação e vigor: Lote 01 - Sementes recém colhidas (safra 2006); Lote 02- Sementes recém colhidas (safra 2006) e submetidas ao envelhecimento acelerado por 48 horas a $41^{\circ} \mathrm{C}$ e $100 \%$ UR, segundo metodologia descrita por Marcos Filho (1999); Lote 03- Sementes recém colhidas (safra 2006) e submetidas ao envelhecimento acelerado por 72 horas a $41^{\circ} \mathrm{C}$ e $100 \%$ UR (Marcos Filho, 1999); Lote 04- Sementes armazenadas por um ano (safra 2005) com grau de umidade de $33 \% \pm 1$.

Para a realização do trabalho, as sementes provenientes dos 4 lotes foram submetidas aos seguintes testes:

Teste de Tetrazólio - Duas porções com 50 sementes retiradas de cada lote, tiveram os seus pergaminhos removidos manualmente, posteriormente foram submetidas à pré-embebição, com imersão direta em água em caixas gerbox com tela contendo $100 \mathrm{~mL}$ de água destilada, em BOD a $30^{\circ} \mathrm{C}$, por um período de 24 horas. Em seguida, as sementes foram submetidas a duas formas distintas de manuseio dos embriões, como descritas a seguir:

Metodologia 1 - Após o período de préembebição, as sementes tiveram seu endosperma eliminado ao máximo, com o uso de um bisturi, de tal forma que fossem evitados danos ou a exposição dos embriões. A porção do endospema contendo o embrião foi submersa em solução a $0,1 \%$ de 2,3,5 Trifenil Cloreto de Tetrazólio, em ausência de luz, em incubadora BOD a $35^{\circ} \mathrm{C}$, , por um período de 16 horas. Terminado este tempo de coloração, os embriões foram cuidadosamente extraídos da parte remanescente do endosperma, com o auxílio de um bisturi. Em seguida, foram lavados em água corrente 
e mantidos em água até o momento da avaliação (Dias \& Silva, 1986).

Metodologia 2 - Após o período de pré-embebição, os embriões foram removidos do endosperma com o auxílio de um bisturi e submersos em solução a 0,1\% de 2,3,5 Trifenil Cloreto de Tetrazólio, em ausência de luz, em incubadora BOD a $35^{\circ} \mathrm{C}$, por um período que variou de 16 horas. Em seguida, foram lavados em água corrente e mantidos em água até o momento da avaliação (Veira et al., 1998)

Os embriões foram examinados individualmente utilizando-se uma lupa (aumento 6x), externa e internamente, realizando-se um seccionamento longitudinal, observando-se a intensidade de coloração dos tecidos, a localização e a extensão dos danos.

As sementes foram classificadas em três classes: viáveis vigorosas, viáveis não vigorosas e inviáveis, conforme a coloração dos tecidos do embrião e a presença e localização dos danos. Para essa classificação, foram utilizados os seguintes critérios: 1) viáveis vigorosas: embrião externa e internamente íntegro, completamente colorido (róseo brilhante a vermelho carmim); 2) viáveis não vigorosas: extremidade da radícula e/ou dos cotilédones não coloridos ou inteiramente coloridos de vermelho carmim mais forte; 3 ) inviáveis: embrião completamente colorido (coloração amarelada, branco leitoso ou vermelho carmim mais forte); eixo hipocótilo-radícula e/ou ponto de inserção dos cotilédones com o ponto de crescimento apical comprometido (coloração amarelada, branco leitoso ou vermelho intenso); embrião com tecido flácido.
Os resultados foram expressos em $\%$ de sementes obtidas em cada classe.

Teste de Germinação (TG) - utilizaram-se 200 sementes, em quatro subamostras de 50 , semeadas em papel substrato umedecido com água destilada em quantidade equivalente a 2,5 vezes o peso do papel seco. Foram confeccionados rolos que foram mantidos em germinador a $30^{\circ} \mathrm{C}$. As avaliações foram efetuadas aos quinze e trinta dias após a semeadura, computando-se as plântulas normais, anormais e sementes mortas. Os resultados foram expressos em porcentagem média de plântulas normais (Brasil, 1992). O vigor das sementes foi calculado utilizando-se do resultado da primeira contagem de germinação (aos 15 dias), quando foram computadas apenas as plântulas normais.

\section{RESULTADOS E DISCUSSÃO}

Na tabela 1 encontram-se os valores de germinação e vigor encontrados para os diferentes lotes, pelo teste de germinação, em que avaliaram-se a contagem final e primeira contagem de plântulas normais, respectivamente, e pelo teste de tetrazólio metodologias 1 e 2 . Os resultados indicaram que os lotes 1,2 e 3 não diferiram significativamente entre si tanto pelo teste de germinação como pelo de tetrazólio, ao se avaliar a viabilidade utilizando-se a metodologia 2. Quando se utilizou a metodologia 1, constatou-se diferença significativa na viabilidade dos lotes 1,2 e 3, o que não ocorreu no teste de germinação, ao se avaliar a porcentagem de plântulas normais obtidas.

Tabela 1

Valores médios de viabilidade e vigor obtidos no teste de tetrazólio, metodologias 1 (Met. 1) e 2 (Met. 2), e de germinação e primeira contagem de germinação para os 4 lotes de sementes de Coffea arabica L . Viçosa, MG, 2006.

\begin{tabular}{|l|c|c|c|c|c|c|}
\hline \multirow{2}{*}{ Lotes } & \multicolumn{2}{|c|}{ Viabilidade (\%) } & Germinação (\%) & \multicolumn{3}{c|}{ Vigor (\%) } \\
\cline { 2 - 7 } & Tetrazólio Met. 1 & Tetrazólio Met. 2 & Teste de Germinação & Tetrazólio Met. 1 & Tetrazólio Met. 2 & $*$ \\
\hline Lote 1 & $50 \mathrm{~b}^{1}$ & $83 \mathrm{a}$ & $95 \mathrm{a}$ & $35 \mathrm{a}$ & $77 \mathrm{a}$ & $82 \mathrm{ab}$ \\
\hline Lote 2 & $75 \mathrm{a}$ & $85 \mathrm{a}$ & $94 \mathrm{a}$ & $30 \mathrm{a}$ & $70 \mathrm{a}$ & $83 \mathrm{a}$ \\
\hline Lote 3 & $28 \mathrm{c}$ & $83 \mathrm{a}$ & $94 \mathrm{a}$ & $12 \mathrm{~b}$ & $72 \mathrm{a}$ & $79 \mathrm{~b}$ \\
\hline Lote 4 & $5 \mathrm{~d}$ & $45 \mathrm{~b}$ & $40 \mathrm{~b}$ & $0 \mathrm{c}$ & $12 \mathrm{~b}$ & $18 \mathrm{c}$ \\
\hline
\end{tabular}

*-primeira contagem - Teste de Germinação

${ }^{1}$-Médias seguidas pela mesma letra minúscula na coluna não diferem significativamente entre si a $5 \%$ de probabilidade pelo teste de Tukey. 
Verificou-se ainda que o lote 4 apresentou valores de viabilidade e de germinação significativamente inferiores aos demais lotes, conforme os resultados dos testes de germinação e de teste de tetrazólio, em ambas as metodologias. Ainda na Tabela 1, ao se avaliar o vigor das sementes, verifica-se que pela metodologia 1 do teste de tetrazólio os lotes 1 e 2 foram superiores aos lotes $3 \mathrm{e} 4$, sendo este inferior aos demais. Já pela metodologia 2, não houve diferença significativa entre os lotes 1,2 e 3 quanto ao vigor, os quais foram superiores ao lote 4. Pela primeira contagem de germinação, o vigor das sementes do lote 2 foi semelhante ao das sementes do lote $1 \mathrm{e}$ superior ao observado para as sementes dos lotes 3 e 4, não havendo diferença significativa entre o vigor dos lotes 1 e 3. Observa-se ainda, que os valores absolutos de vigor obtidos na primeira contagem de germinação foram bem superiores aos observados na metodologia 1 do teste de tetrazólio. Ao se utilizar a metodologia 2 , verifica-se que o vigor das sementes dos lotes 1,2 e 3 foi semelhante, sendo superior ao do lote 4 , sendo os valores absolutos mais próximos aos obtidos na primeira contagem de germinação.

A metodologia 1, na qual o embrião foi exposto à solução de tetrazólio junto com parte do endosperma, mostrou-se pouco eficiente, pois apresentou problemas referentes à coloração do embrião, sendo que muitos embriões não coloriam e alguns coloriam somente as extremidades, dificultando assim a interpretação dos resultados. Nesta metodologia, tanto os valores de viabilidade como os de vigor das sementes não representaram os valores encontrados no teste de germinação, provavelmente, pelo fato de que a solução de tetrazólio não chegou ao embrião, dificultando assim a coloração e avaliação. Neste caso, embriões que não desenvolveram coloração ideal podem ter sido considerados inviáveis, quando na realidade a ausência de coloração pode ter sido ocasionada pela presença de parte do endosperma aderido ao embrião dificultando o contato direto deste com a solução de tetrazólio. Observou-se também que em muitos embriões houve desenvolvimento de coloração vermelho intenso na parte superior dos cotilédones ou na parte inferior do eixo hipocótilo-radícula, provavelmente, pelo fato dessas regiões estarem mais expostas à solução de tetrazólio do que as demais. No entanto, essa metodologia se mostrou mais prática causando menos danos ao embrião no momento da sua extração.

Os valores de viabilidade encontrados nos lotes, analisando-se a metodologia 2, em geral foram $10 \%$ inferiores aos de germinação. Geralmente há diferença entre germinação e viabilidade, mas esse valor não excede à $5 \%$. Esse valor um pouco superior ao normal pode ser justificado devido a danos causados no embrião no momento de sua retirada, e dependendo da intensidade e do local desse dano embriões anteriormente viáveis podem ter sido classificados como inviáveis.

Araújo et al. (1997), estudando ambas as formas de exposição do embrião, obtiveram resultados semelhantes e citam que, a metodologia na qual o embrião é colocado na solução de tetrazólio junto com uma porção do embrião, dificulta a tomada de decisão quanto à viabilidade da semente. No presente trabalho, quando se utilizou a metodologia com os embriões sendo colocados diretamente na solução de tetrazólio, estes problemas não existiram, e com isso os resultados se mostraram mais próximos aos encontrados no teste de germinação, comprovados pelo alto coeficiente de correlação encontrado entre os testes (Tabela 2 e 3 ).

Tabela 2

Coeficientes de correlação linear entre os resultados do teste de germinação (TG) e os do teste de tetrazólio (Metodologias 1 e 2) realizados em 4 lotes de sementesde Coffea arabica L. , Viçosa, MG, 2006

\begin{tabular}{|l|c|c|c|}
\hline & TG & Metodologia 1 & Metodologia 2 \\
\hline TG & 1 & $0,765452611 \mathrm{~ns}$ & $0,984764556^{*}$ \\
\hline Metodologia 1 & & 1 & $0,786467096 \mathrm{~ns}$ \\
\hline Metodologia 2 & & & 1 \\
\hline
\end{tabular}

*-significativo a $5 \%$ de probabilidade pelo teste $\mathrm{F}$ ns-não significativo

Tabela 3

Coeficientes de correlação linear entre os resultados de vigor obtidos na primeira contagem do testes de germinação (TG) e o teste de tetrazólio (metodologias 1 e 2) realizados em 4 lotes de sementes de Coffea arabica L., Viçosa, MG, 2006

\begin{tabular}{|l|c|c|c|}
\hline & TG & Metodologia 1 & Metodologia 2 \\
\hline TG & 1 & $0,825816948 \mathrm{~ns}$ & $0,987125292 *$ \\
\hline Metodologia 1 & & 1 & $0,808554694 \mathrm{~ns}$ \\
\hline Metodologia 2 & & & 1 \\
\hline
\end{tabular}

*-significativo a 5\% de probabilidade pelo teste $\mathrm{F}$ ns-não significativo 
Os resultados mostrados nas tabelas 2 e 3 mostram que o coeficiente de correlação entre o teste de germinação e a metodologia 2 foi positiva e altamente significativa $(r=0,984764556$ para germinação e $r=0,987125292$ para vigor). Resultados semelhantes foram encontrados por Pasha e Das (1982) comparando a viabilidade de sementes de soja, obtidas no teste de tetrazólio, com os resultados do teste de germinação. Para a metodologia 1 os coeficientes de correlação encontrados foram não significativos $(r=0,765452611$ para germinação e $\mathrm{r}=0,825816948$ para vigor).

Portanto, no teste de tetrazólio, utilizando-se as duas metodologias, foi observado que a metodologia 2, na qual se coloca o embrião exposto na solução de tetrazólio, foi mais precisa para se estimar a viabilidade (Figura 1) e o vigor dos lotes (Figura 2).

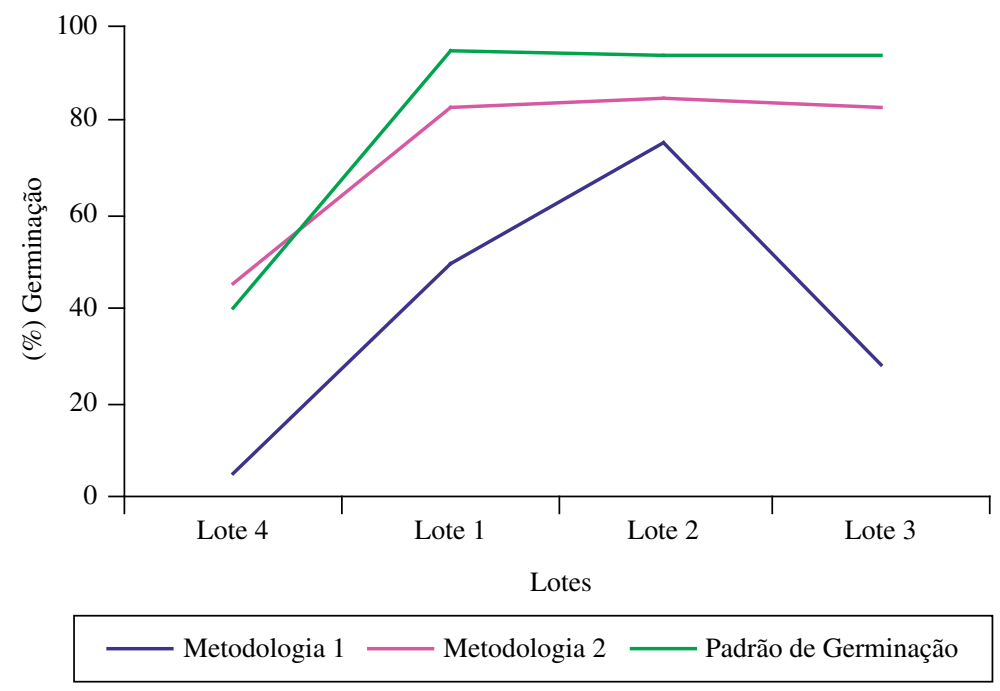

Figura 1. Resultados médios obtidos nos testes de germinação e de tetrazólio (metodologias 1 e 2) realizados em 4 lotes de sementes de Coffea arabica L. Viçosa, MG, 2006.

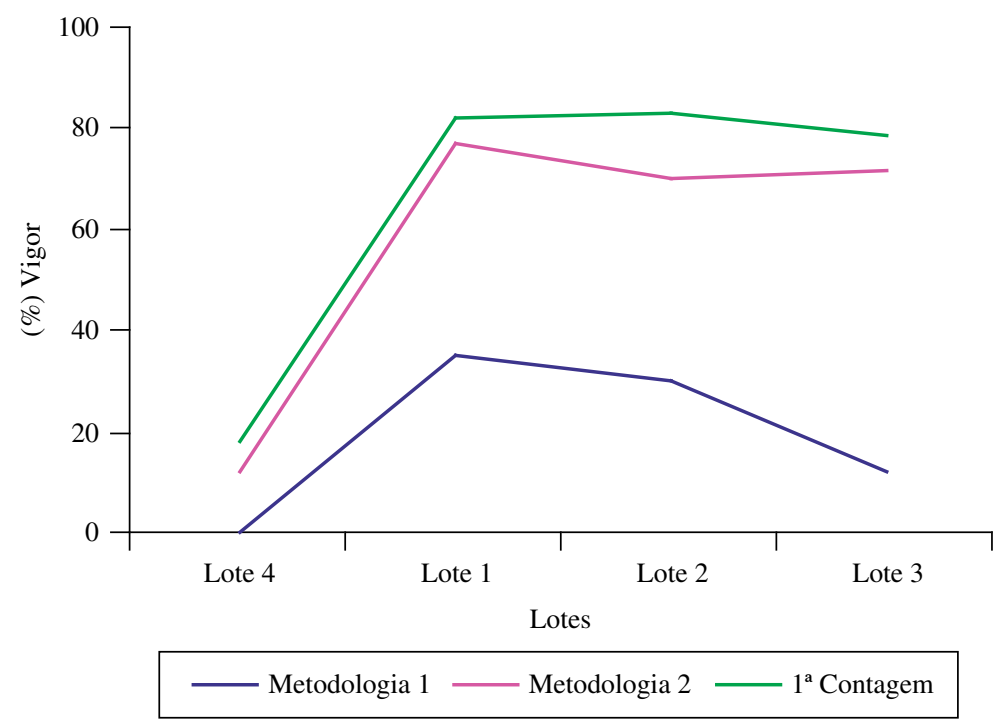

Figura 2. Resultados médios de vigor obtidos na $1^{\mathrm{a}}$ contagem de germinação e no teste de tetrazólio (metodologias 1 e 2) realizados em 4 lotes de sementes de Coffea arábica L. , Viçosa, MG, 2006. 


\section{CONCLUSÕES}

Avaliando-se os resultados encontrados, o teste de tetrazólio foi eficiente para avaliar a viabilidade e o vigor das sementes, quando se utilizou a metodologia

\section{REFERÊNCIAS BIBLIOGRÁFICAS}

ARAÚJO, R.F.; ALVARENGA, E.M.; LIMA, W.A.A.; DIAS, D.C.F.S.; ARAÚJO, E.F. 1997. O uso do teste de tetrazólio para avaliar a viabilidade de sementes de café (Coffea arabica L.). Informativo ABRATES, Curitiba, v. 7, n. $1 / 2$, p. 109.

BARROS, D. I.; DIAS, D.C.F.S; BHERING, M. C.; DIAS, L.A.S.; ARAÚJO, E. F. 2005. Uso do teste de tetrazólio para avaliação da qualidade fisiológica de sementes de abobrina (Cucurbita pepo L.). Revista Brasileira de Sementes, Pelotas - RS, v. 27, n. 2, p. 165-172.

BENDAÑA, F.E. 1962. Fisiologia de las semillas de café. I. Problemas relativos al almacenamiento. Café, Turialba, 4 (15): 93-6.

BHERING, M. C.; DIAS, D.C.F.S; BARROS, D.I. 2005. Adequação da metodologia do teste de tetrazólio para sementes de melancia. Revista Brasileira de Sementes, Pelotas - RS, v. 27, n. 1, p. 176-182.

BHERING, M.C.; SILVA, R.F.; ALVARENGA, E.M.; DIAS, D.C.F.S.; PENA, M.F. 1996. Avaliação da viabilidade e vigor das sementes de feijão-de-vagem (Phaseolus vulgaris L.) pelo teste de tetrazólio. Viçosa: UFV, 38p. Boletim técnico.

BHERING, M.C.; SILVA, R.F.; ALVARENGA, E.M.; DIAS, D.C.F.S.; PENA, M.F. 1999. Metodologia do teste de tetrazólio em sementes de feijão. In: Krzyzanowski, F.C.; Vieira, R.D.; França Neto, J.B. (eds.). Vigor de sementes: conceitos e testes. Londrina: ABRATES, cap. 8.3, p. 8.3-1 - 8.3-10.

BITTENCOURT, S.R.M.; VIEIRA, R.D. 1996. Use of reduced concentrations of tetrazolium solutions for the evaluation of the viability of peanut seed lots. Seed Science and Technology, Zürich, v. 2, n. 1, p. 75-82.

BITTENCOURT, S.R.M.; VIEIRA, R.D.; RODRIGUES, T.J.D. 1997. Criteria for peanut seed pre-conditioning for the tetrazolium test. Seed Science and Technology, Zürich, v. 25, p. $337-342$.

BITTENCOURT, S.R.M.; VIEIRA, R.D. 1999. Metodologia do teste de tetrazólio em sementes de amendoim. In: KRZYZANOWSKI, F.C.; VIEIRA, R.D.; FRANÇA NETO, J.B. Vigor de sementes: conceitos e testes. Londrina: ABRATES, cap. 8.2, p. 8.2-1 - 8.2-8.

BRASIL. 1992. Ministério da Agricultura e da Reforma Agrária. Regras para análise de sementes. Brasília: SNDA/DNDV/ CLAV, $365 \mathrm{p}$.

COSTA, N.P.; MARCOS FILHO, J. 1994. O emprego do teste de tetrazólio na avaliação da qualidade da semente de soja. Informativo ABRATES, Londrina, v. 4, n. 2, p. 53-62.

DELOUCHE, J.C.; BASKIN, N.C. 1973. Accelerated aging techniques for predicting the relative storability of seed lots. Seed Science and Technology, Zürich, v.1, p. $427-452$. na qual o embrião é exposto diretamente na solução de tetrazólio. A utilização da metodologia na qual embrião é exposto à solução de tetrazólio junto com parte do endosperma, embora mais prática, mostrou-se pouco eficiente, necessitando mais estudos.

DELOUCHE, J.C.; STILL, T.W.; RASPET, M.; LIENHARD, M. 1976. O teste de tetrazólio para viabilidade da semente. Brasília: AGIPLAN, $103 \mathrm{p}$.

DIAS, M.C.L.L.; ALVES, S.J. 2001A. Avaliação da viabilidade de sementes de Panicum maximum jacq pelo teste de tetrazólio. Informativo ABRATES, Londrina, v. 11, n.2, p. 317.

DIAS, M.C.L.L.; ALVES, S.J. 2001B. Avaliação da viabilidade de sementes de Brachiaria brizantha (Hoscst. Ex A. Rich) Stapf pelo teste de tetrazólio. Informativo ABRATES, Londrina, v. 11, n. 2, p. 317.

DIAS, M.C.L.L.; BARROS, A.S.R. 1999. Metodologia do teste de tetrazólio em sementes de milho. In: Krzyanowski, F.C.; Vieira, R.D.; França Neto, J.B. (Ed). Vigor de sementes: conceitos e testes. Londrina: ABRATES, cap. 8.4, p. 8.4-1 - 8.4.10

DIAS, M.C.L.L.; SILVA, W.R. 1986. Determinação da viabilidade de sementes de café através do teste de tetrazólio. Pesquisa Agropecuária Brasileira, Brasília, 21 (11): 1139-1145, nov.

EICHELBERGER, L; MORAES, D.M. 2001. Preparo de sementes de quiabo (Abelmoschus esculentus (L.) Moench) para o teste de tetrazólio. Revista Brasileira de Sementes, Londrina, v. 23, n. 1, p. 154-158.

FIGUEIREDO, T.G. 2000. Adaptação do teste rápido (pH do exudato - fenolftaleína), para estimar a viabilidade de sementes de cafeeiro (Coffea arábica L.). Lavras: UFLA, 2000. 57 p. Dissertação (Mestrado em Fitotecnia). Universidade federal de Lavras.

FRANÇA NETO, J.B.; PEREIRA, L.A.G.; COSTA, N.P.; KRZYZANOWSKI, F.C.; HENNING, A.A. 1988. Metodologia do teste de tetrazólio em sementes de soja. Londrina: EMBRAPA-CNPSo, $60 \mathrm{p}$.

FRANÇA NETO, J.B.; KRZYZANOWSKI, F.C.; COSTA, N.P. 1999. Metodologia do teste de tetrazólio em sementes de soja. In: Krzyzanowski, F.C.; Vieira, R.D.; França Neto, J.B. (eds). Vigor de sementes: conceitos e testes. Londrina: ABRATES, cap. 8.5, p. 8.5-1 - 8.5-28.

MARCOS FILHO, J. 1999. Teste de envelhecimento acelerado. In: Krzyanowski, F.C.; Vieira, R.D.; França Neto, J.B. (eds.). Vigor de sementes: conceitos e testes. Londrina-PR: ABRATES, cap. 2, p. 1-24.

PASHA, M.R.; DAS, R.K. 1982. Quick viability test of soybean seed by using tetrazolium chloride. Seed Science and Technology, Zurich, v. 10, n. 2, p. 651-655.

POPINIGIS, F. 1977. Fisiologia da semente. Brasília, MA/ AGIPLAN, 289P.

SERA, G.H.; MIGLIORANZA, E. 2000. Avaliação visual do poder germinativo de sementes de café por exudatos. In: Simpósio de Pesquisa dos Cafés do Brasil, L., 2000, Poços de Caldas. Resumos Expandidos... Brasília - DF: Embrapa Café Minasplan. 
SILVA, W.R. E DIAS, M.C.L.L. 1985. Interferência do teor de umidade das sementes de café na maturação de sua qualidade fisiológica. Pesquisa Agropecuária Brasileira., 20(5): 551-60.

VARGAS, E.V. 1955. Como conservar la semilla del café. Rev. Agric., Com. e Ind., Panamá, 13 (26): 44.

VIEIRA, M.G.G.C.; PINHO, E.V.R.V. 1999. Metodologia do teste de tetrazólio em sementes de algodão. In: Krzyzanowski,
F.C.,Vieira, R.D., França Neto, J.B. Vigor de sementes: conceitos e testes. Londrina: ABRATES, cap. 8.1, p. 8.1-1 - 8.1-13.

VIEIRA, M.G.G.C.; GUIMARÃES, R.M.; PINHO, E.V. R. V.; GUIMARÃES, R.J.; OLIVEIRA, J.A. 1998. Testes rápidos para determinação da viabilidade e da incidência de danos mecânicos em sementes de cafeeiro. Lavras: UFLA, 34 p. Boletim Agropecuário, 26. 